\title{
Inibição da migração larval em tecidos de camundongos imunizados com antígenos de Toxocara vitulorum
}

Silvia Helena Silvestre de PAULA';

Wilma Aparecida STARKEBUZETTI';

Maria Francisca NEVES ${ }^{1}$; Fabiano Pan FERREIRA ${ }^{1}$

\section{Correspondência para:} WILMA APARECIDA STARKE BUZETTI

Departamento de Biologia e Zootecnia Faculdade de Engenharia de Ilha Solteira (FEIS)

Avenida Brasil, 56

15385-000- Ilha Solteira-SP

starke@bio.feis.unesp.br

Recebido para publicação: 06/10/2003 Aprovado para publicação: 15/03/2005

1 - Departamento de Biologia e Zootecnia da Faculdade de Engenharia de Ilha Solteira (FEIS) da UNESP, Ilha Solteira - SP

\section{Resumo}

Três grupos de camundongos foram imunizados com os seguintes antígenos de Toxocara vitulorum : fluido perientérico (Pe) do parasita adulto, antígenos extrato solúvel bruto (Ex) e excretor/secretor (ES) de larvas infectantes. Estes três grupos foram comparados com o grupo controle, não imunizado. Todos os grupos foram desafiados uma semana após a imunização com ovos infectantes deste parasita e necropsiados em três períodos diferentes após o desafio: sete horas, quatro dias e 30 dias pós-infecção. Realizou-se a contagem de ovos e de larvas nas fezes dos camundongos e o grupo imunizado com antígeno do fluído perientérico (Pe) foi o que eliminou a maior quantidade de larvas. Após a necropsia, realizou-se a retirada do intestino delgado, intestino grosso, fígado, pulmão, coração, cérebro e músculos (diafragma, língua e quadríceps femoral). Estes tecidos sofrearam digestão péptica e as larvas foram identificadas e contadas em cada um deles. O maior número de larvas foi encontrado no intestino grosso no período de sete horas após o desafio, em todos os grupos examinados, porém, este número foi significativamente inferior nos grupos imunizados. Com quatro dias após o desafio, as larvas concentravam-se, preferencialmente, no fígado e pulmões, e os grupos imunizados apresentaram uma quantidade muito menor de larvas, significativo para o fígado e pulmão em relação ao grupo controle. No período de 30 dias após o desafio, as larvas recuperadas no cérebro e no músculo, mesmo que em pequena quantidade, demonstraram capacidade de alcançar estes tecidos. A efetividade desta imunização baseou-se na redução do número de larvas de T. vitulorum no fígado no quarto dia pós-infecção em relação ao controle, que foi de $86 \%, 79 \%$ e $58 \%$ para o antígeno Ex, Pe e ES, respectivamente. O camundongo foi considerado um modelo apropriado para estudar a relação parasita-hospedeiro das infecções por T. vitulorum.

\section{Introdução}

Toxocara vitulorum é um nematódeo ascaridídeo de intestino delgado de ruminantes, principalmente de bovinos e búfalos com idades inferiores a quatro meses $^{1,2,3,4}$. Há décadas muitos pesquisadores vem observando que o presente parasita é um dos principais causadores de mortalidade quando os animais não são medicados convenientemente ${ }^{5,6}$.
As larvas deste nematódeo precisam realizar migrações teciduais para órgãos tais como fígado, pulmões e outros órgãos antes de atingirem o estádio adulto no intestino delgado. Estas larvas, nos animais mais resistentes como os hospedeiros habituais adultos e os hospedeiros erráticos (camundongos, ratos, coelhos, hamsters, galinhas e outros), podem permanecer sem se desenvolver em estado de hipobiose ${ }^{7}$. No entanto, estas larvas aprisionadas, 
principalmente no fígado e nos pulmões das búfalas imunologicamente deprimidas pela prenhez, podem migrar para a glândula mamária, possivelmente pela corrente sangüínea, e serem transferidas para os bezerros búfalos, principalmente nos primeiros 10 dias após o nascimento durante o processo de amamentação ${ }^{8}$. Vários autores já comprovaram a presença de larvas infectantes de T. vitulorum no colostro/leite de búfalas nos primeiros 20 dias após o parto $^{8,9,10,11}$. A transmissão transmamária do parasita aos bezerros búfalos, onde as mães podem ser consideradas hospedeiros intermediários, dificulta muito o tratamento, uma vez que as larvas podem permanecer protegidas da ação de muitas drogas quimioterápicas. Desta forma, Barriga e Omar ${ }^{12}$ sugeriram o uso de vacinação das mães como uma medida preventiva para controlar a infecção de seus bezerros.

Além disso, pesquisas recentes têm demonstrado que as búfalas apresentam elevados níveis de anticorpos anti-T. vitulorum no soro durante o periparto e no colostro nos primeiros 20 dias pós-parto e estes anticorpos são transferidos passivamente para os bezerros búfalos. Apesar destes anticorpos não evitarem que os animais se infectem, estes podem apresentar um papel importante no processo de expulsão dos parasitas adultos do trato digestório ${ }^{2,4,13}$. Ferreira ${ }^{14}$ caracterizando os antígenos de $T$. vitulorum a partir de larvas infectantes (L3) como ES (excretor/secretor) e Ex (extrato solúvel bruto) e a partir de adultos como o líquido perientérico (Pe) por SDS-PAGE e Western blotting, utilizou colostros e soros de búfalas, assim como soros de seus bezerros. Neste estudo, ficou confirmado a presença de anticorpos IgG anti-T. vitulorum e foi sugerido que os búfalos eram capazes de armar uma reposta imune contra este parasita.

Tendo em vista que estudos para testar imunologicamente antígenos de helmintos em animais de grande porte como os búfalos é difícil e oneroso, alguns autores tentaram em animais de laboratório, como
Amerasinghe et al. ${ }^{15}$ em camundongos e Barriga e Omar ${ }^{12}$ em coelhos. Como T. vitulorum realiza migrações somáticas em tecidos de camundongo, demonstrado por Chauhan e Pande ${ }^{16}$ através de infecções experimentais, foi possível a utilização deste hospedeiro como modelo experimental para verificar a resposta imune contra este parasita. Desta forma, Amerasinghe et al. ${ }^{15}$ através de prévia imunização parenteral de camundongos com diferentes antígenos de T. vitulorum, obtiveram uma ótima proteção contra a reinfecção e a migração larval. Os animais foram desafiados com ovos infectantes de $T$. vitulorum sete dias após a última imunização e sacrificados para contagens de larvas, principalmente no fígado, pulmões e rins, cinco dias após o desafio. Os antígenos mais efetivos na proteção imunogênica foram o Pe dos parasitas adultos e o ES de larvas infectantes de T. vitulorum.

Baseado na boa resposta imunogênica dos camundongos, o objetivo da presente pesquisa foi o de utilizar o mesmo modelo experimental para testar se os antígenos ES, Ex e Pe obtidos em nosso laboratório ${ }^{2,4,14}$ utilizados na imunização de camundongos seriam capazes de bloquear a passagem de larvas pela mucosa intestinal e inibir a migração para órgãos vitais como o fígado, pulmões, cérebro e musculatura.

\section{Materiais e Métodos}

\section{Local, animais e manejo}

Foram utilizados 60 camundongos (Mus musculus) machos adultos e da linhagem Rockefeller que foram alojados em gaiolas apropriadas e permaneceram em sala climatizada a $25^{\circ} \mathrm{C}$, onde receberam água e ração à vontade.

\section{Obtenção de ovos e antígenos}

Para a obtenção de ovos infectantes, fêmeas de T. vitulorum foram colhidas de bezerros búfalos de um a dois meses de vida naturalmente infectados. O parasitismo dos animais foi avaliado através de contagem de 
ovos por grama de fezes (OPG), de acordo com a técnica de Whitlock ${ }^{17}$. Os animais positivos foram tratados com anti-helmíntico à base de Piperazina na dosagem de $100 \mathrm{a}$ $150 \mathrm{mg} / \mathrm{kg}$ de peso vivo do animal para expulsão dos parasitas adultos pelas fezes. Estes foram colhidos e lavados várias vezes com detergente neutro (Extran ${ }^{\circledR} \mathrm{MA} \mathrm{02}$, Merk) e enxaguados com água destilada. A dissecação das fêmeas foi realizada para a retirada do útero. Os ovos foram liberados e mantidos em placas de Petri contendo água destilada numa profundidade de 0,5 a 1,0 $\mathrm{cm}$ à temperatura ambiente $\left(25^{\circ} \mathrm{C}\right)$, de acordo com Starke-Buzetti, Machado e Zoccoler-Seno ${ }^{4}$. A segmentação dos ovos foi acompanhada por exames diários ao microscópico óptico, até o desenvolvimento das larvas infectantes dentro dos ovos (25 a 30 dias).

Os antígenos ES e Ex, obtidos de larvas infectantes e o Pe de adultos, machos e fêmeas, foram obtidos e gentilmente cedidos por Souza et al. ${ }^{2}$ e Ferreira ${ }^{14}$.

\section{Imunização e infecção experimental dos camundongos}

Para a imunização, os camundongos foram divididos em quatro grupos com cinco animais cada: um grupo foi imunizado com o antígeno Pe, outro grupo com Ex e o outro com Pe. O quarto grupo não recebeu antígeno, mas apenas o adjuvante. Estes antígenos foram homogeneizados em adjuvante de Freund completo e incompleto na concentração protéica de $20 \mathrm{mg} / \mathrm{ml}$ e aplicados intra-peritonialmente, na dose de $200 \mathrm{ml}$ por animal e por aplicação (no total de três aplicações), de acordo com o seguinte esquema: Na primeira semana, apenas com adjuvante completo e nas subsequentes, segunda e quarta semanas apenas com o incompleto. Uma semana após a última imunização, todos os camundongos foram desafiados com ovos infectantes de T. vitulorum. A dose única de 2500 ovos/animal suspendidos em $1 \mathrm{ml}$ de tampão fosfato a $0,01 \mathrm{M} \mathrm{e} \mathrm{pH} \mathrm{7,4} \mathrm{(PBS),}$ foi administrada oralmente, utilizando-se uma seringa de insulina graduada adaptada a uma cânula esofágica. Logo após a infecção experimental, para realização dos exames coprológicos, as fezes dos cinco camundongos existentes em cada gaiola foram colhidas a cada duas horas dentro de seis horas e na última colheita o intervalo foi de apenas uma hora porque os animais foram sacrificados sete horas após o desafio. Das fezes colhidas, pesou-se $2 \mathrm{~g}$ que foram homogeneizadas em $10 \mathrm{ml}$ de água de torneira e coadas em gaze. Desta suspensão fecal tomou-se uma alíquota de $10 \%$ para a contagem dos ovos e das larvas presentes, com auxilio do microscópio de luz branca. Pormotivos não determinados, conseguiuse apenas $1 \mathrm{~g}$ de fezes por colheita nos grupos ES e Ex.

\section{Necropsia dos camundongos e digestão das amostras de tecidos para obtenção de larvas}

Após o desafio com ovos infectantes, os animais de todos os grupos foram necropsiados em três etapas, sete horas, quatro dias e 30 dias após o desafio. Os camundongos foram anestesiados, sacrificados e os tecidos colhidos. Os órgãos exteriorizados foram os intestinos delgado e grosso, fígado, pulmão, coração, e o conjunto de músculos ("pool" de diafragma, língua e quadríceps femural) e cérebro. Os órgãos foram imediatamente colocados, individualmente, em tubos de vidro para digestão péptica em um solução contendo $0,7 \%$ de pepsina e $0,7 \%$ de $\mathrm{HCl} 12 \mathrm{~N}$, em banho-maria por horas à $37^{\circ} \mathrm{C}$ e com agitação constante. Em seguida, o digerido total de cada órgão foi centrifugado a $2000 \mathrm{rpm}$ por cinco minutos. Dez por cento do total da suspensão obtida de cada tecido foi examinado sob microscópio de luz e as larvas presentes nesta amostra foram contadas. Após as contagens, a taxa de inibição da migração larval (IL) foi calculada com base na quantidade de larvas contadas no fígado dos camundongos necropsiados quatro dias após a infecção, segundo a fórmula proposta por Amerasinghe et al. ${ }^{15}$.

$\mathrm{IL}=$ Número de larvas nos animais controle -

Número de larvas nos animais imunizados x 100

Número de larvas nos animais controle 


\section{Análise Estatística}

Os dados foram analisados segundo a análise de variância de acordo com o ftorial 4x3, em delineamento inteiramente casualizado com cinco repetições. A comparação de média de larvas contadas no material digerido (tecidos dos camundongos ) foi realizada pelo teste de Tukey.

\section{Resultados}

Pelo exame fecal (Tabela 1), verificouse que os animais imunizados com o antígeno Pe apresentaram maior número de larvas e de ovos nas fezes, ou seja quase o dobro (1,9x), em comparação com o grupo controle não imunizado. Nestes dois grupos, o número de larvas foi 4,8 a 6,5 vezes superior em relação ao de ovos, indicando que as larvas foram rapidamente eclodidas dentro do trato digestório dos animais. Estes parasitas (ovos e larvas) começaram a ser visualizados nas fezes já na primeira colheita, ou seja, duas horas após a infecção experimental e a quantidade deste material continuou elevando levemente por até sete horas (última colheita), nos grupos controle e imunizado com Pe. Foi constatado também a presença de larvas e de ovos nas fezes dos animais imunizados com os antígenos ES e Ex em número semelhante e ao do controle. Nestes dois últimos grupos, o pico máximo de eliminação de larvas ocorreu quatro horas após o desafio. Notase também que nos grupos ES e Ex o número de ovos equiparou-se ao de larvas, indicando menor chance de eclosão e penetração larval pela parede intestinal.

A tabela 2 ilustra o número médio de larvas de $T$. vitulorum encontrado no intestino delgado e grosso, no fígado, nos pulmões, no coração, no cérebro e no músculo, nos diferentes períodos (sete horas, quatro e 30 dias) após o desafio, nos animais imunizados e não imunizados. Sete horas após o desafio, a maior concentração de larvas de $T$. vitulorum foi observada no intestino grosso dos animais não imunizados, com $526 \pm 231$ (média \pm desvio padrão). Neste órgão, estes números foram inferiores aos dos grupos imunizados com os antígenos Pe $(246 \pm 46,7)$, Ex $(284 \pm 182)$ e ES $(44 \pm 30,5)$ em relação ao grupo não imunizado $(p<0,05)$. Somente os grupos imunizados com o antígeno Ex e o controle apresentaram larvas no pulmão, embora em pequeno número.

No quarto dia após o desafio, houve uma profunda redução no número de larvas no intestino grosso, porém observou-se um aumento no fígado, órgão mais parasitado, principlamente no grupo controle (134 \pm 77). No entanto, nos grupos imunizados estes valores foram significativamente inferiores aos verificados no grupo controle, sendo: $28 \pm 22,8$ para o antígeno Pe, $18 \pm 34,9$ para o antígeno Ex, $56 \pm 59,4$ para o antígeno ES e $134 \pm 77$ para o controle. A taxa de inibição da migração larval do intestino grosso para o fígado foi $86 \%, 79 \%$ e $58 \%$, respectivamente para o antígeno Ex, Pe e ES. Em seguida, o órgão mais parasitado foi o pulmão, mas somente no grupo controle e no imunizado com ES, apresentando número de larvas $(20 \pm 7,1)$ significativamente superior em relação aos grupos imunizados com o antígeno Pe (6士 $8,94)$ e $\operatorname{Ex}(8 \pm 13)$. Algumas larvas $(2 \pm$ $4,5)$ também estavam presentes no cérebro e no músculo dos camundongos do grupo controle e apenas no músculo do grupo imunizado com Pe.

Trinta dias após o desafio, os animais controles apresentavam $2 \pm 4,5$ e $4 \pm 5,8$ larvas, respectivamente no cérebro e nos músculos. Foram observadas $2 \pm 4,5$ nos camundongos imunizados com os antígenos ES e Pe, mas apenas nos músculos. No entanto, algumas larvas ainda continuavam aprisionadas no pulmão dos animais imunizados com Pe $(2 \pm 4,5)$.

\section{Discussão}

Os antígenos de $T$. vitulorum testados no presente trabalho (Ex, ES e Pe) 
proporcionaram diferentes níveis de proteção contra a migração e a sobrevivência larval em camundongos.

O número de ovos e larvas eliminados nas fezes dos camundongos, durante as primeiras sete horas após o desafio foi muito baixa em todos os grupos examinados. Dos 2500 ovos administrados oralmente, apenas 3\% dos parasitas (ovos e larvas) foram eliminados pelo grupo controle e $5,8 \% ; 4 \%$ e 3,2\%, respectivamente pelos grupos Pe, Ex e ES. No entanto, o grupo Pe rejeitou praticamente o dobro de parasitas em relação ao controle. Como o antígeno Pe é o fluído perientérico dos parasitas adultos, que nos ascaridídeos é rico em componentes alergênicos ${ }^{18,19,20}$, acreditase que este antígeno seja mais eficiente em provocar uma reação de hipersensibilidade ao nível de mucosa para aumentar a contratibilidade intestinal e a secreção de mediadores inflamatórios e favorecer a expulsão dos ovos/larvas com o bolo fecal dificultando assim a penetração larval. Já nos grupos imunizados com os antígenos ES e Ex a quantidades dos parasitas eliminados pelas fezes foi semelhante ao do grupo controle, com a diferença de que a maior quantidade de ovos não eclodidos foram contados nestes dois grupos imunizados. Dos poucos trabalhos existentes na literatura sobre a infecção experimental com T. vitulorum, somente Barriga e Omar ${ }^{12}$ realizaram a contagem de parasitas eliminados nas fezes, mas em coelhos. Estes autores ${ }^{12}$ colheram a fezes dos coelhos do primeiro ao terceiro dia após a infecção experimental e verificaram que eles eliminaram $10 \%$ dos parasitas administrados na primeira infecção, $4 \%$ na segunda e 34\% na terceira. Os mesmos autores verificaram também que após a primeira infecção, os ovos praticamente dominaram nas fezes, mas após a terceira infecção a maioria dos parasitas encontravam-se na fase livre larval. Este experimento demonstrou que os coelhos desenvolveram imunidade contra $T$. vitulorum, principalmente após a terceira infecção experimental, pois praticamente 1 /
3 dos parasitas administrados foram eliminados. No presente trabalho, as fezes foram colhidas dentro do período máximo de sete horas após o desafio e é possível que se as colheitas fossem realizadas em um período superior, o número de parasitas recuperados nas fezes fosse superior, como pode ser observado pela quantidade crescente de larvas sendo eliminadas pelos camundongos do grupo imunizado com Pe.

Nos animais necropsiados sete horas após o desafio, observou-se que a grande maioria das larvas encontravam-se ainda no intestino grosso. As larvas estavam presentes em maior quantidade neste órgão, em todos os grupos examinados, no entanto, o grupo não imunizado foi o que apresentou o maior número de larvas, quase o dobro do número dos demais. Este resultado sugere que as larvas no grupo controle poderiam estar conseguindo atravessar a mucosa com mais facilidade para atingir a circulação sangüínea ou cair na cavidade abdominal e em seguida seguir a rota migratória em direção às outras vísceras, particularmente o fígado e o pulmão. Cabe salientar, que neste período (sete horas) as larvas também foram observadas no fígado e nos pulmões no grupo controle, apesar dos pulmões dos animais do grupo Ex apresentarem também algumas larvas. Quando os ovos infectantes de $T$. vitulorum foram administrados oralmente por Chauhan e Pande ${ }^{16} \mathrm{em}$ camundongos, as larvas eclodiram ao longo do intestino duas horas após a infecção, mas com pico em torno de oito horas no ceco, onde este órgão foi considerado pelos autores como o principal local de eclosão e penetração das larvas. Já no fígado, estas larvas foram encontradas seis horas após, mas com pico em torno do quarto dia. Os resultados do presente trabalho estão e concordância com Chauhan e Pande ${ }^{16}$ quanto ao tempo e local de invasão das larvas pela mucosa intestinal. Outros autores citaram também o íleo e o ceco como locais de penetração larvas de $T$. canis em camundongos ${ }^{21}$. Decorridos quatro dias do desafio, o número de larvas praticamente 
Tabela 1 - Resultados das contagem de larvas e de ovos de Toxocara vitulorum por grama de fezes de camundongos $(\mathrm{n}=5)$ imunizados com diferentes antígenos (Pe, Ex e ES) de T. vitulorum e não imunizados (controle), desafiados com ovos infectantes (2500 ovos/animal) do parasita e sacrificados sete após o desafio

Número de larvas e de ovos deToxocara vitulorum/grama de fezes/grupo de animais

\begin{tabular}{cccccccccc}
\hline \multirow{2}{*}{$\begin{array}{c}\text { Horas após o } \\
\text { desafio }\end{array}$} & \multicolumn{2}{c}{ Controle } & \multicolumn{2}{c}{ Antígeno Pe } & \multicolumn{2}{c}{ Antígeno Ex } & \multicolumn{3}{c}{ Antígeno ES $^{3}$} \\
\cline { 2 - 9 } & Larvas & Ovos & Larvas & Ovos & Larvas & Ovos & Larvas & Ovos \\
\hline $0-2$ & 0 & 0 & 0 & 0 & 0 & 10 & 0 & 10 \\
$2-4$ & 05 & 0 & 20 & 25 & 50 & 30 & 10 & 20 \\
$4-6$ & 30 & 05 & 40 & 0 & 10 & 0 & 0 & 0 \\
$6-7$ & 30 & 05 & 60 & 0 & 0 & 0 & 0 & 10 \\
\hline Total & 65 & 10 & 120 & 25 & 60 & 40 & 40 & 40 \\
\hline
\end{tabular}

1 = antígeno líquido perientérico do adulto; 2 = antígeno extrato solúvel da larva; 3 = antígeno excretor/secretor da larva

Tabela 2 - Número médio e desvio padrão de larvas de Toxocara vitulorum nos tecidos de camundongos imunizados com os antígenos (Ex, ES, Pe) e os não imunizados (controle) nos diferentes períodos após o desafio com ovos infectantes deste parasita

\begin{tabular}{|c|c|c|c|c|c|c|c|c|}
\hline \multirow{2}{*}{$\begin{array}{c}\text { Período } \\
\text { Pós-desafio }\end{array}$} & \multirow{2}{*}{$\begin{array}{l}\text { Grupo } \\
(\mathrm{n}=5)\end{array}$} & \multicolumn{7}{|c|}{ Número Médio \pm Desvio Padrão de larvas de Toxocara vitulorum } \\
\hline & & ID & IG & Fígado & $\begin{array}{c}\text { Coraçã } \\
0\end{array}$ & Pulmão & Cérebro & Músculo \\
\hline \multirow{4}{*}{7 horas } & Controle & $10 \pm 10$ & $526 \pm 231$ & $4 \pm 5,5$ & 0 & $6 \pm 13,4$ & 0 & 0 \\
\hline & $\mathrm{Pe}$ & $\begin{array}{l}16 \pm \\
35,8\end{array}$ & $\begin{array}{l}246 \pm \pm \\
46,7^{*}\end{array}$ & 0 & 0 & 0 & 0 & 0 \\
\hline & Ex & $16 \pm$ & $284 \pm 182^{*}$ & 0 & 0 & $8 \pm 13$ & 0 & 0 \\
\hline & ES & $4 \pm 8,9$ & $\begin{array}{c}44 \underset{30,5^{*} *}{ \pm}\end{array}$ & 0 & 0 & 0 & 0 & 0 \\
\hline \multirow{4}{*}{4 dias } & Controle & 0 & $4 \pm 8,9$ & $134 \pm 77$ & 0 & $20 \pm 7,1$ & $2 \pm 4,5$ & $6 \pm 8,9$ \\
\hline & $\mathrm{Pe}$ & 0 & 0 & $28 \pm \overline{2} 2,8^{*}$ & 0 & $6 \pm 8,9 *$ & $2 \pm 4,5$ & 0 \\
\hline & Ex & $2 \pm 4,5$ & 0 & $18 \pm 34,9 *$ & 0 & $8 \pm 13^{*}$ & 0 & 0 \\
\hline & $\mathrm{ES}$ & 0 & 0 & $56 \pm 59,4^{*}$ & 0 & $20^{-} \pm 7,1$ & 0 & 0 \\
\hline \multirow{4}{*}{30 dias } & Controle & 0 & 0 & 0 & 0 & 0 & $2 \pm 4,5$ & $4 \pm 5,8$ \\
\hline & $\mathrm{Pe}$ & 0 & 0 & 0 & 0 & $2 \pm 4,5$ & 0 & $2 \pm 4,5$ \\
\hline & Ex & 0 & 0 & 0 & 0 & 0 & 0 & 0 \\
\hline & ES & 0 & 0 & 0 & 0 & 0 & 0 & $2 \pm 4,5$ \\
\hline
\end{tabular}

$\mathrm{ID}=$ intestino delgado

$\mathrm{IG}=$ intestino grosso

$\mathrm{n}=$ número de camundongos por grupo

$*^{*}=$ indicam diferença significativa em relação ao controle $(\mathrm{p}<0,05) ;{ }^{* *}=$ indicam diferença significativa em relação ao controle e aos antígenos Pee Ex $(p<0,05)$.

zerou nos intestinos, significando que as larvas conseguiram escapar da reação inflamatória dirigindo-se a diversos órgãos ou foram destruídas e eliminadas. Segundo Abo-Shehada, Al-Zubaidy e Herbert ${ }^{21}$, camundongos vacinados com diferentes antígenos de $T$. canis, uma reação inflamatória rica em células mononucleares (granuloma na fase inicial) ocorre ao redor da larva no local da sua penetração na mucosa do intestino, bem como um aumento da quantidade de muco, cinco a nove horas após o desafio, na tentativa de impedir a entrada de larvas pela mucosa intestinal.

Quatro dias após o desafio, a maior concentração larval encontrava-se no fígado; resultados semelhantes foram obtidos por Chauhan e Pande ${ }^{16}$, Amerasinghe et al. ${ }^{15} \mathrm{e}$ Barriga e Omar ${ }^{12}$. De acordo com Chauhan e Pande ${ }^{16}$, as rotas principais de migração de larvas do intestino do camundongo para o fígado são: através da cavidade abdominal, seguida da veia porta e dos linfonodos mesentéricos. No presente trabalho, no entanto, o número destas larvas no fígado variou significativamente entre os diferentes grupos testados. No grupo controle, o número de larvas foi 7,4; 4,7 e 2,4 vezes superior ao Ex, Pe e ES, respectivamente. Como nos camundongos dos grupos Ex e Pe, maior número de larvas foram encontradas no intestino grosso e menor número no fígado, pôde-se concluir que 
houve uma maior eficiência na capacidade destes dois antígenos em inibir a migração larval do intestino para os demais órgãos, principalmente para o fígado. O grupo ES, no entanto, além de apresentar menor quantidade de ovos e larvas nas fezes e de larvas na parede do intestino grosso às sete horas, apresentou um número mais elevado de larvas no fígado, no quarto dia pósinfecção, demonstrando menor eficiência do antígeno ES na inibição da migração larval.

Ainda com base na quantidade de larvas presentes no fígado, quatro dias após o desafio, calculou-se o índice de inibição da migração larval para este órgão que foram de $86 \%$ para o antígeno Ex, $79 \%$ para o antígeno Pe e $58 \%$ para o antígeno ES. Embora estes resultados dos índices de proteção tenham sido inferiores aos de Amerasinghe et al..$^{15}$ que obtiveram uma efetividade de inibição da migração de 100\%, $92 \%$ e $82 \%$, respectivamente, os resultados $\mathrm{da}$ presente pesquisa indicam uma excelente proteção imunológica. Amerasinghe et al. ${ }^{15}$ imunizaram os camundongos através de injeções subcutâneas dos antígenos sem adjuvante (não foi mencionada a concentração dos antígenos) diferindo portanto da metodologia adotada no presente trabalho, onde a via de inoculação foi a intra-peritoneal com adjuvante de Freund. Por outro lado, estes índices imunológicos de proteção detectados na presente pesquisa foram superiores em relação ao T. canis $^{21,22}$, onde reportaram uma proteção leve que variou de 27 a $40 \%$ dependendo da forma de imunização dos camundongos.

Nenhuma larva foi observada no coração dos animais controles ou imunizados e desta forma não possível aferir a rota de migração das larvas para os pulmões através do coração como constatado por Chauhan e Pande ${ }^{16}$.

Ainda no quarto dia após o desafio, o segundo órgão mais parasitado por larvas, seguido do fígado, foram os pulmões, mas com número bem reduzido de larvas. No entanto, somente o grupo ES não diferiu estatisticamente do grupo controle no número de larvas, reforçando mais uma vez a ineficiência deste antígeno no controle da migração larval. Algumas larvas ainda foram visualizadas no conteúdo digerido do cérebro e do músculo dos animais controles, e duas larvas também foram detectadas no pulmão e no músculo de animais imunizados com Pe. Segundo Abo-Shehada; Herbert ${ }^{23} \mathrm{e}$ Abo-Shehada, Al-Zubaidy e Hebert ${ }^{21}$, a mucosa intestinal, o fígado e os pulmões são órgãos que participam nos mecanismos de defesa de camundongos contra a migração larval. As larvas podem ser expelidas com as fezes ou ficarem aprisionadas em granulomas no intestino, no fígado e nos pulmões, ou serem expelidas juntamente com a expectoração brônquica.

Muitos autores pesquisam o cérebro e o músculo como referência para quantificar as larvas após a imunização. Segundo Dvoroznakova, Boroskova e Tomasovicova ${ }^{24}$, as larvas de $T$. canis alcançavam o cérebro de camundongos entre 7 e 21 dias após a infecção. Estes autores determinaram que a imunização de camundongos reduziu a migração de larvas em $52,1 \%$ e $44,2 \%$ para o cérebro e $29 \%$ e $16 \%$ para os músculos, respectivamente para os antígenos larvais ES e Ex de T. canis e sugeriram que os antígenos foram eficientes em acelerar uma resposta imune celular (ES) e aumentar a resposta imune humoral específica (Ex). No presente trabalho, as larvas estavam presentes no cérebro e no músculo já no quarto dia. No entanto, 30 dias após o desafio, estas larvas foram recuperadas em número muito reduzido (2 a 4 larvas) e somente no cérebro dos animais controles. Já no músculo, estas larvas foram evidenciadas no controle e nos grupos imunizados com ES e Pe.

Os resultados indicam que os antígenos obtidos de T. vitulorum foram capazes de estimular o sistema imune de camundongos e de serem efetivos na proteção, embora parcial, pois algumas larvas foram capazes de evadir à resposta imune. Com relação à infecção nos búfalos, sabe-se que o T. vitulorum estimula imunologicamente 
o hospedeiro, como pode ser verificado pelos altos níveis de anticorpos IgG no soro de bezerros búfalos e no soro e colostro de búfalas no periparto ${ }^{2,4,13,14}$. No entanto, as larvas ainda conseguem evadir dos granulomas e migrar para a glândula mamária, nas búfalas prenhes e os mecanismos envolvidos não são conhecidos. Assim, é desejável conhecer os mecanismos imune-humoral-celulares do hospedeiro que podem estar relacionados neste processo além dos mecanismos imune-moduladores do parasita para deprimir o sistema imunológico do hospedeiro. Como pesquisas desta natureza são difíceis de serem efetuadas em animais do porte dos bubalinos, este trabalho ratifica os camundongos como um modelo adequado para o estudo da imunoparasitologia do $T$. vitulorum.

\section{Conclusões}

A imunização de camundongos com os antígenos Pe, Ex e ES foram eficazes no controle da migração larval de T. vitulorum para os tecidos, demonstrando que estes antígenos possuem potencialidade imunogênica. O camundongo foi considerado um modelo apropriado para estudar a relação parasitahospedeiro das infecções por T. vitulorum.

\section{Larval migration inhibition in tissues of mice immunized with Toxocara vitulorum antigens}

\section{Abstract}

Three groups of mice were immunized agaisnt three different Toxocara vitulorum antigens: perienteric fluid (Pe) of adults and excretory/ secretory (ES) and soluble extracts (Ex) of infective larvae. A group of non-immunized animals was considered the control group. All groups were challenged one week after the third immunization with T. vitulorum infective eggs and necropsied at three different periods after the challenge: seven hours, four and 30 days. Eggs and larvae counts in the feces of mice were accomplished and revealed that Pe immunized group eliminated the highest number of larvae. Small and large intestines, liver, lungs, heart, brain and muscle (diaphragm, tongue e quadriceps femoris) were removed, digested by peptical digestion and larvae were identified and counted. The higher number of larvae was found in the large intestine seven hours after the challenge in all examined groups; however, this number was significantly lower in animals of the immunized groups. On day four after the challenge, larvae were more often found in the liver and lungs, and the immunized groups had lower numbers of larvae than in the control groups. On day 30 after the challenge low numbers of larvae were recovered in the brain and muscle. The effective immunization against larval migration based on the rate of reduction of the larvae present in the liver on day four after infection was of $82 \%, 79 \%$ and $58 \%$ for Ex, Pe and ES antigen, respectively.

\section{Referências}

1 NEVES, M. F. ; STARKE-BUZETTI, W. A.; CASTRO, A. M. M. G. Mast cell and eosinophils in the wall of the gut and eosinophils in the blood stream during Toxocara vitulorum infection of the water buffalo calves (Bubalus bubalis). Veterinary Parasitology, v. 113, p.
Key-words: Mus musculus. Toxocara vitulorum. Immunization. Mice. 
M.C. Curso natural das helmintoses gastrintestinais em búfalos no Município de Andradina -SP. Arquivo Brasileiro Medicina Veterinária e Zootecnia, Belo Horizonte, v. 35, p. 651-664, 1983.

4 STARKE-BUZETTI, W. A.; MACHADO, R. Z.; ZOCCOLER-SENO, M. C. An enzyme-linked immunosorbent assay (ELISA) for detection of antibodies against Toxocara vitulorum in water buffaloes. Veterinary Parasitology, Amsterdam, v.97, p.55-64, 2001.

5 DAS, K.M.; SINGH, G. B. Calf ascariasis in India. A nine years survey with special reference to "Hetrazan". The British Veterinary Journal, London, v. 111, p. 347, 1955.

6 LÁU, H. D. Doenças dos bezerros. In:__. Doenças em búfalos no Brasil: diagnósticos, epidemiologia e controle. Brasília: EMBRAPA-SPI, 1999. p. 23-56.

7 OMAR, H. M.; BARRIGA, O. O. Biology and pathophysiology of Toxocara vitulorum infections in a rabbit model. Veterinary Parasitology, Amsterdam, v. 40, p. 257-266, 1992.

8 ROBERTS, J. A. The life cycle of Toxocara vitulorum in Asian buffalo (Bubalus bubalis). International Journal for Parasitology, Elmsford, v. 20, p. 833-840. 1990.

$9 \mathrm{MIA}$, S. et al. The route of infection of buffalo calves by Toxocara (Neoascaris) vitulorum Tropical Animal Health and Production, Edinburgh, v 7, p.153-156, 1975.

10 STARKE, W. A; MACHADO, R. Z.; ZOCOLLER, M. C. Transmissão transmamária de larvas de nematóides gastrintestinais a bezerros búfalos. II. Larvas de Toxocara vitulorum. Arquivo Brasileiro de Medicina Veterinária e Zootecnia, Belo Horizonte, v.44, p.97103, 1992.

11 WARREN, E. G. Observations on the migration and development of Toxocara vitulorum in natural and experimental hosts. International Journal for Parasitology, Elmsford, v. 1, p. 85-99, 1971.

12 BARRIGA, O. O.; OMAR, H. M. Immunity to Toxocara vitulorum repeated infections in a rabbit model Veterinary Immunology and Immunopathology, Amsterdam, v. 33, p. 249-260, 1992.

13 RAJAPAKSE, R. P. V. J.; LLOYD, S.; FERNANDO, S. T. Toxocara vitulorum: maternal transfer of antibodies from buffalo cows (Bubalus bubalis) to calves and levels of infection with $T$. vitulorum in the calves. Research in Veterinary Science, v. 57, n. 1, p.81-87, 1994.

14 FERREIRA, F. P. Obtenção e caracterização de antígenos de Toxocara vitulorum por SDS-Page e "Western blotting". 2002. 53 p. Dissertação (Mestrado - Sistema de Produção Animal) - Faculdade de Engenharia de Ilha Solteira, Universidade Estadual Paulista, Ilha Solteira, 2002.

15 AMERASINGHE, P. H. et al. Antigen-induced protection against infection with Toxocara vitulorum larvae in mice. Parasitology Research, Belfast, v. 78, n. 8, p. 643-647, 1992.

16 CHAUHAN, P. P. S.; PANDE, B. P. Migratory behaviour and histopathology of Neoascaris vitulorum larvae in albino mice. Indian Journal of Experimental Biology, New Delhi, v. 10, p. 193-200, 1972.

17 WHITLOCK, H. V. Some modifications of the McMaster helminth egg-counting technique and apparatus. Journal Science Research Australian, v. 21, p. 177-180, 1948.

$18 \mathrm{KUO}, \mathrm{C}$. Y.; YOO, T. J. A new allergen from the perienteric fluid of Ascaris suum with respect to charges. International Archives of Allergy and Applied Immunology, v. 54, n. 4, p. 308-314, 1977.

19 McWILLIAM, A. S.; STEWART, G. A.; TURNER, K. J. An immunochemical investigation of the allergens from Ascaris suum perienteric fluid. Cross-reactivity, molecular weight distribution and correlation with phosphorylcholine-containing components. International Archives of Allergy and Applied Immunology, v. 82, n. 2, p. 125-132, 1987.

20 RHODES, M. B.; STAUDINGER, L. A. Antigens in perienteric fluid of Ascaris suum as detected through antibodies in pigs orally inoculated with fully embryonated eggs. Veterinary Parasitology, v. 12, p. 179-186, 1983.

21 ABO-SHEHADA, M. N.; AI-ZUBAIDY, B. A.; HERBERT, I. V. Acquired immunity to Toxocara canis infection in mice. Veterinary Parasitology, Amsterdam, v. 38, n. 4, p. 289-298, 1991.

22 CONCEPCION, J. E.; BARRIGA, O. O. Transfer of infection-induced immune protection to Toxocara canis in a mouse model. Veterinary Immunology and Immunopathology, v. 9, p. 371-382, 1985.

23 ABO-SHEHADA, M. N. ; HERBERT, I. V. Variations in innate resistance to experimental Toxocara canis infection in two strains of mice. Veterinary Parasitology, v. 33, p. $297-307,1989$.

24 DVOROZNAKOVA, E.; BOROSKOVA, Z.; TOMASOVICOVA, O. Immune responses in mice immunized with Toxocara canis antigens. Helminthologia, v. 39, p. 59-66, 2002. 